Document downloaded from:

http://hdl.handle.net/10251/77665

This paper must be cited as:

Ruiz Sánchez, T.; Roorda, MJ. (2011). Assessing planning decisions by activity type during the scheduling process. Transportmetrica. 7(6):417-442.

doi:10.1080/18128602.2010.520276.

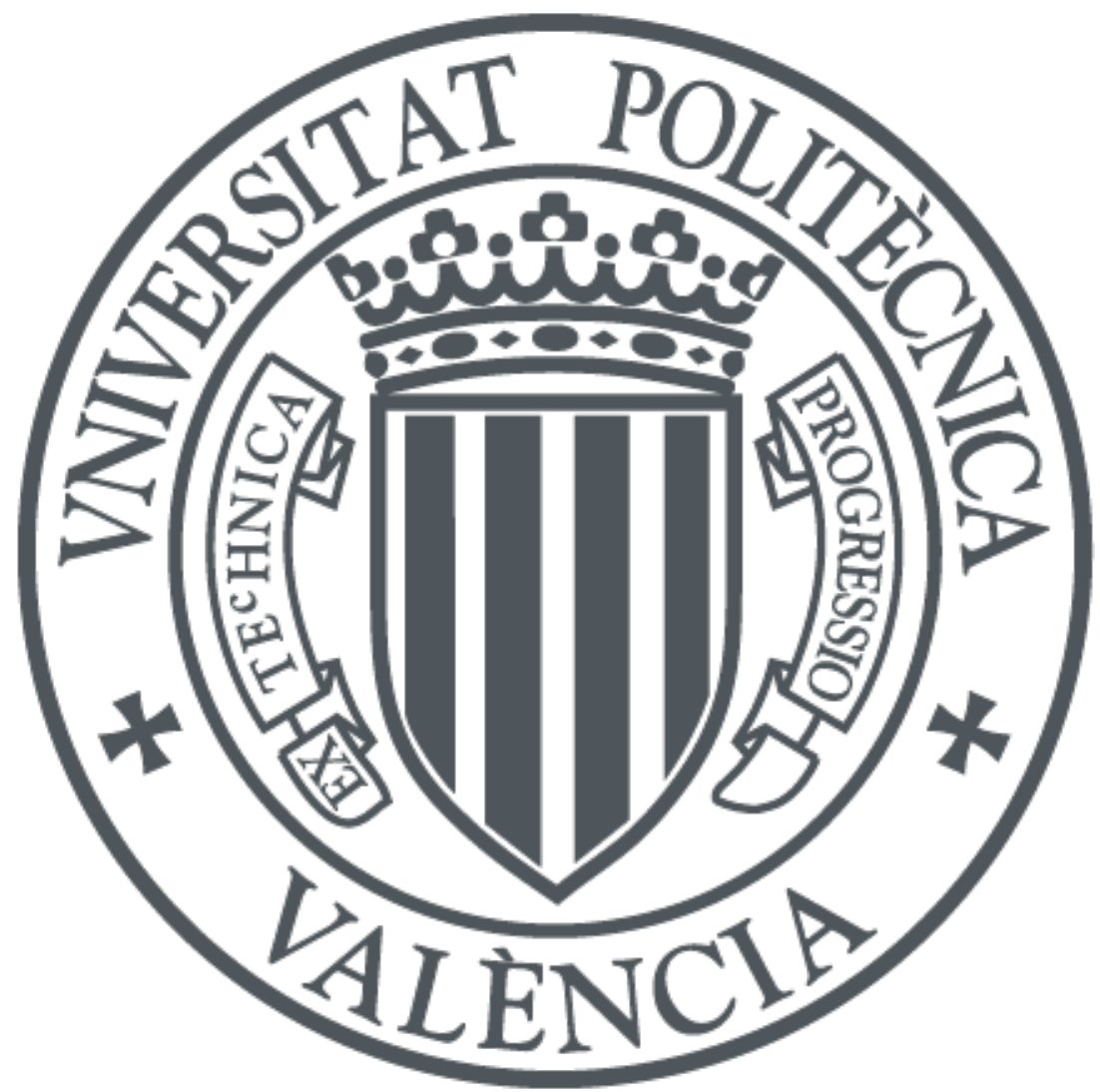

The final publication is available at

http://dx.doi.org/10.1080/18128602.2010.520276

Copyright Taylor \& Francis

Additional Information 


\title{
Assessing Planning Decisions by Activity Type \\ During the Scheduling Process
}

\author{
Tomás Ruiz* \\ Assistant Professor, \\ Transport Department \\ School of Civil Engineering \\ Technical University of Valencia \\ Camino de Vera s/n \\ 46022 Valencia, Spain \\ Tel: $(+34) 963877370$ \\ Fax: (+34) 963877370 \\ Email: truizsa@tra.upv.es \\ Matthew J. Roorda \\ Assistant Professor, \\ Department of Civil Engineering \\ University of Toronto \\ 35 St. George Street \\ Toronto, Ontario, M5S 1A4, Canada \\ Tel: (+1 416) 978-5976 \\ Fax: (+1 416) 978-5054 \\ Email: roordam@ecf.utoronto.ca
}

\begin{abstract}
Existing activity-based models still make assumptions about scheduling decision processes that are not well-informed by empirical evidence. In this paper, a step forward is taken to better understand the activity-scheduling process and to improve activity-based models. In particular, different planning decision mechanisms depending on several activity type classifications are explored.

First, models describing the planning of several aggregate activity types are considered. For these activities, three planning decisions are studied: location, planning time horizon and rescheduling. The "with whom" planning decision is also studied when sub-types of recreational/entertainment activities are investigated in depth.

Significant differences are found in modeling results for each activity type and sub-type and each planning decision. These results confirm the existence of different mechanisms underlying the activity-travel decision process when activity types and sub-types are considered. Important conclusions related to the improvement of microsimulation models are highlighted.
\end{abstract}

KEYWORDS: Activity-Travel Scheduling, Planning Decision Process, Activity-Based Models 


\section{INTRODUCTION}

Several sequential models that explicitly address the process of scheduling behaviour have been developed. Some of them are SCHEDULER (Gärling et al., 1994), AMOS (Pendyala et al., 1995, 1998), SMASH (Ettema et al., 1994, 2000), PCATS (Kitamura et al., 1996), GISICAS (Kwan, 1997), ALBATROSS (Arentze and Timmermans, 2000), AURORA (Timmermans et al.,2001; Joh et al., 2003, 2004), TASHA (Miller and Roorda, 2003), FAMOS (Pendyala et al., 2005) and FEATHERS (Arentze et al, 2006). Recent advances in household activity models considering the scheduling process can be found in Timmermans and Zhang (2009). Many of the models currently in operation were created using activity pattern data from travel surveys, resulting in a need to make assumptions about the underlying activity scheduling process.

TASHA, for example, makes assumptions for various components of activity scheduling, including the following:

- TASHA assumes a priority-based procedure for generating activities, in which the order of activity types to be inserted into a person's activity schedule is deterministic (work, school, joint social/recreation/personal business, joint shopping, individual social/recreation/personal business, and finally individual shopping). While there is some empirical basis that this is on average the most likely order in which activities are inserted into the activity schedule (Roorda and Miller, 2005), the assumption of determinism is too strong. The degree of preplanning and the likelihood of rescheduling of activities of all types are potentially better represented stochastically.

- Because no data are collected for in-home activities in the underlying travel survey data, TASHA does not attempt to distinguish between in-home activity types, even though there may be significant substitution effects between some types of in-home activities and out-of-home activities that require travel.

- The frequency of joint activities (activities conducted with others) is assumed to be independent of the frequency of individual activities. These activities could well be subject to substitution effects as well.

Similarly, ALBATROSS has a scheduling agent, which can only test the outcome of the scheduling process, and relies on a priori assumptions because process information was not available (Timmermans, 2001).

Currently, data describing specific aspects of the activity scheduling process are available. Following the seminal attempts by Hayes-Roth and Hayes-Roth (1979) using a verbal protocol, Ettema et al. (1994) developed Magic, a computer programme for self completion of activity (re-)scheduling tasks. Doherty and Miller (2000) developed CHASE, a computeraided self-interview of activity scheduling for households, allowing users to record their scheduling decisions over a multi-day period. Other similar software running on the Internet or on handheld computers, were used by Lee et al. (2000), Lee and McNally (2001) and Rindsfüser et al. (2003). Ruiz (2005) used the Internet as the only tool to collect data on the activity scheduling process. The Toronto Activity Panel Survey (Roorda and Miller, 2004) used several methods to collect activity scheduling data, including CHASE in the first survey wave. Bellemans et al. (2008) and Clark and Doherty (in press a) used GPS data to automatically track activity rescheduling decisions. Hato (2010) recently developed a small, portable travel-activity measuring instrument that requires no entry from respondents. 
First steps towards a deeper comprehension of the activity scheduling process have been recently taken through empirical analysis of the available data. Ruiz et al. (2005), Ruiz and Timmermans (2006) and Auld et al. (2008) studied resolution of activity scheduling conflicts. Mohammadian and Doherty (2005), Doherty (2005), Lee and McNally (2006), Mohammadian and Doherty (2006) van Bladel et al. (2009) and Akar et al. (2009) analyzed activity scheduling time horizon. Clark and Doherty (in press b) also studied time horizon and the impact of a single decision on the rest of the schedule. Kang et al (2009) studied activity priority during the scheduling process.

Finally, some studies have analyzed several facets of the activity scheduling process, or even global scheduling adjustment (Joh, Polak and Ruiz, 2005; Joh, Doherty and Polak, 2005). In particular, Doherty (2006) found that activity types with similar spatial/temporal/interpersonal flexibility do not share stable attributes (frequency, duration, involved persons, travel time, and location). These results suggest that traditional activity type classifications cannot be used as the only means to explain when and how activity patterns are formed. It is necessary to consider other attributes as well, which may serve to better explain how and why travel behavior is subsequently structured and executed. In the same line, empirical analysis carried out by Doherty and Mohammadian (2007) clearly does not support the assumption that activities are planned in accordance to a fixed hierarchy of activity types. In this study, duration proved to be the most significant activity characteristic when explaining how activity-travel tours are planned. But Clark and Doherty (2008) have recently found that activity type is the most often preplanned activity attribute, followed by location, start time, involved persons, and end time. For trips, the mode type and start time are most often planned first, followed by involved persons and end time. Ruiz and Roorda (2008) studied several decisions during the activity scheduling process including location, time horizon, activity modification and with whom. They found that characteristics of the observed schedule and activities have the greatest influence over scheduling decisions. Several significant correlations among activity scheduling decisions were also identified. Scheduling activity types have recently been modelled together in a study of activity-agenda formation (Habib and Miller, 2009).

The diversity of results obtained so far indicates that there is a need to continue studying the role of activity type classification in the activity scheduling process. In this research we postulate that different types of activities follow different mechanisms underlying the scheduling decision process. The type of activity itself has a significant influence on several characteristics of this process. If this is true, when simulating this process there would be a need to consider different models for each activity type. We expect that in each model, different variables are significant in explaining the same scheduling decision. Our objective is to test this hypothesis using a rich dataset that allows us to study differences even among activity sub-types.

First, multivariate probit models are used to explore scheduling mechanisms underlying activity location choice, preplanning and rescheduling for several aggregate activity types. Then, sub-types of recreational/entertainment activities are analyzed in-depth to detect differences in scheduling decisions. It was possible to include in the latter analysis with whom information (whether or not activities are planned to be carried out with companions), because this planning decision was collected without misunderstanding for recreation/entertainment activities. But it was not feasible to analysis sub-types of other kinds of activities in depth because of sample size restrictions. 
We consider that the activity scheduling decision process is defined as "the planning and execution of activity-related decisions over time" (Doherty, 2000). The point of our modelling effort is to show that there are relationships between when an activity is planned, where it is planned, with whom it is planned, and the stability of the scheduled activity. We want to identify whether out of home activities, for example, are planned more in advance, or are harder to reschedule.

Location and with whom are two of the most important elements that are part of the scheduling process, and therefore our joint modelling approach tries to capture this. For location, the relationships between time and space in activity planning are well established (Hagerstrand's space-time prisms (1970) are the obvious example). Commitments to others (as represented in the "with whom" variable) surely influence the planning horizon and the difficulty of rescheduling. Additionally, planning to carry out an activity with other people requires joint scheduling decisions to make their agendas consistent (Arentze and Timmermans, 2009), which justifies the need to study the with whom scheduling decision.

The paper is organised as follows. After this introduction the characteristics of the dataset used are presented. Then, results from the modelling exercises are analysed. The paper finishes with some conclusions and discussion.

\section{DATA}

The Travel Activity Panel Survey (TAPS) is an in-depth longitudinal survey of activity and travel scheduling processes, undertaken on an initial random sample of 270 households in Toronto and 250 households in Quebec City, Canada (Doherty et al, 2004; Roorda et al, 2005). The TAPS survey consisted of three waves, each of which focussed on different elements of the activity scheduling process. The data used in this study comes from the first wave of Toronto sample. A computerized activity scheduling survey instrument, entitled CHASE $^{\odot}$ (Computerized Household Activity Schedule Elicitor), which was first developed by Doherty and Miller (2000) were used to collect the data. Each household in the sample was provided, for one week, a notebook computer with the CHASE software, which resembled a computerized day-timer. At the outset of the survey week, the household was interviewed to obtain socio-economic information, the software was customized for the family, and adult household members were asked to enter all activities that were already planned for the week. Each day, respondents were asked to update their activity diary with any new activities that had been planned, any plans for future activities that had changed, and any changes to activities done that day that were not executed as originally planned.

Several variables were collected for each activity that was entered or modified in the schedule. These variables included the activity type, location, start-time, and duration of the activity, the mode(s) of transportation used to get to the activity, the persons that were involved with the respondent on the activity, any children that were under the care of the respondent during the activity, and when the activity was originally planned.

Activity types were collected by means of two classifications. Respondents were first asked to classify their activity in nine categories (aggregate classification), including basic needs, work/school, household obligations, drop-off/pick-up, shopping, services, recreation/entertainment, social, and other. Then, respondents were asked to define in detail the activity using their own words or selecting a pre-determined activity definition 
(disaggregate classification). Recreation/entertainment activities included: hobbies, exercise or active sports, spectator events/theatre, playing/parks, regular TV programs, unspecific TV, watching video, relaxing/napping/reading, email/internet and other recreation/entertainment.

For each planned activity, respondents were asked "When did you originally make the decision to add this activity? (i.e. at what point were you relatively sure about when where and with whom this activity would take place)." The resulting responses were coded into the following general categories (see Clarke and Doherty (2008b) for more detail):

- Spontaneous

- Planned on the same day

- Planned days before

- Planned weeks / months / years ago

- Routine

- Unknown / can't recall / missing

The purpose of this question was to ascertain the types of activities that form the "skeleton" of the schedule, or in other words, the part of the schedule that is routine or planned in advance and which therefore forms the spatio-temporal structure around which other more spontaneously planned activities are scheduled. For the analysis and discussion in this paper, these categories are aggregated into "preplanned activities" (including routine activities and those planned days/weeks/months/years ago), and "spontaneous" activities (including activities recorded as spontaneous and activities planned on the same day). As other dependent variables are binary, we simplified this one to have homogeneous categorizations of dependent variables and to avoid dimensionality problems with the four decision dimensions. (i.e. instead of 16 possible combinations $(2 \times 2 \times 2 \times 2)$ over the 4 binary dimensions, we would be dealing with 48 combinations $(2 \times 2 \times 2 \times 6)$ for each activity type without aggregation). There is a trade-off between the number of dimensions and the number of categories in each dimension, and we have opted to including more scheduling choice dimensions.

The CHASE survey also recorded any activity additions, modifications or deletions that are made to the schedule over the course of the week. Thus, it is possible with this data set to compare the attributes of activities that are executed as originally planned to those that are modified. This can indicate the degree of permanence associated with activities entered into the schedule. After data cleaning, the total number of activity records in the Toronto Wave 1 survey was 40055, including activity additions, modifications and deletions.

As shown in Table 1, basic needs, household obligations and recreation/entertainment activities are more often planned to be carried out at home. The rest of types of activities are more likely to be planned for out-of-home locations.

All types of activities are more frequently executed as planned. Basic needs activities are least likely to be modified or deleted prior to their execution and work/school activities are most likely to be modified or deleted prior to their execution.

Basic needs, work/school and drop-off/pick-up activities are more often preplanned. Household obligations, services and recreation/entertainment activities are almost equally likely to be preplanned or as they are to be spontaneous. Other activity types are most often spontaneously planned. 
Recreation/entertainment activities and household obligations are more frequently planned to be carried out alone. As expected, social activities are mostly planned with others. Basic needs activities are as likely to be planned to be performed alone or with others.

TABLE 1 Aggregate classification of activity types and planning decisions

\begin{tabular}{|c|c|c|c|c|c|c|c|c|c|c|c|c|c|c|c|c|}
\hline \multirow{2}{*}{$\begin{array}{l}\text { Planning } \\
\text { decision }\end{array}$} & \multicolumn{2}{|c|}{ At Home } & \multicolumn{2}{|c|}{$\begin{array}{l}\text { Out-of- } \\
\text { Home }\end{array}$} & \multicolumn{2}{|c|}{ As Planned } & \multicolumn{2}{|c|}{$\begin{array}{l}\text { Modified/ } \\
\text { deleted }\end{array}$} & \multicolumn{2}{|c|}{ Preplanned } & \multicolumn{2}{|c|}{ Spontaneous } & \multicolumn{2}{|c|}{$\begin{array}{c}\text { With } \\
\text { Others* }\end{array}$} & \multicolumn{2}{|c|}{ Alone* $^{*}$} \\
\hline & total & $\%$ & total & $\%$ & total & $\%$ & total & $\%$ & total & $\%$ & total & $\%$ & total & $\%$ & total & $\%$ \\
\hline Basic Needs & 14647 & 94.2 & 908 & 5.8 & 13692 & 88 & 1863 & 12 & 10368 & 66.7 & 5187 & 33.3 & 484 & 53.3 & 424 & 46.7 \\
\hline Work/School & 1002 & 24.8 & 3034 & 75.2 & 3211 & 79.6 & 825 & 20.4 & 2889 & 71.6 & 1147 & 28.4 & & & & \\
\hline $\mathrm{HH}$ Obligations & 5281 & 96.7 & 182 & 3.3 & 4649 & 85.1 & 814 & 14.9 & 2869 & 52.5 & 2594 & 47.5 & 56 & 30.8 & 126 & 69.2 \\
\hline Drop-off/Pick-up & 129 & 7.7 & 1546 & 92.3 & 1386 & 82.7 & 289 & 17.3 & 1073 & 64.1 & 602 & 35.9 & & & & \\
\hline Shopping & 6 & 0.4 & 1422 & 99.6 & 1223 & 85.6 & 205 & 14.4 & 456 & 31.9 & 972 & 68.1 & & & & \\
\hline Services & 68 & 10.1 & 602 & 89.9 & 559 & 83.4 & 111 & 16.6 & 373 & 55.7 & 297 & 44.3 & & & & \\
\hline Rec/Entert & 6624 & 84.1 & 1252 & 15.9 & 6698 & 88 & 1178 & 12 & 3940 & 88 & 3936 & 12 & 2784 & 35.3 & 5092 & 64.7 \\
\hline Social & 914 & 45.3 & 1105 & 54.7 & 1699 & 84.7 & 306 & 15.3 & 897 & 44.7 & 1108 & 55.3 & 1492 & 74.4 & 513 & 25.6 \\
\hline Other & 987 & 75.2 & 325 & 24.8 & 1141 & 87 & 171 & 13 & 531 & 40.5 & 781 & 59.5 & & & & \\
\hline Total & 29658 & & 10376 & & 34258 & & 5762 & & 23396 & & 16624 & & 4816 & & 6155 & \\
\hline
\end{tabular}

(*) Data about the "with whom" planning decision was only available for the following activities: Basic Needs out-of-home, Household Obligations out-of-home, and Recration/Entertainment and Social activities

As shown in Table 2, exercise or active sports, attending events/theater and other recreation/entertainment activities are more frequently planned to be carried out out-of-home. The rest of recreation/entertainment activity sub-types are mostly planned to take place at home.

All sub-types of recreation/entertainment activities are more frequently executed as planned. However, some differences are evident. Activities related to watching regular or unspecific TV programs or video and email/Internet activities are much less often modified or deleted prior to execution than the other sub-types of recreation/entertainment activities.

Hobbies, exercise or active sports and attending events/theatre are typically preplanned. Playing/parks activities are almost equally preplanned or spontaneous. The rest of activity types are mostly spontaneously planned.

Hobbies, exercise or active sports, regular or unspecific TV programs, relaxing, napping, reading, emailing and internet are more frequently planned to be carried out alone. Spectator events, theatre, watching videos, and other recreation/entertainment are more often planned with other(s). Playing/parks activities are almost equally likely to be planned alone or with others. 


\section{TABLE 2 Sub-classification of Recreation/Entertainment activities and planning decisions}

\begin{tabular}{|c|c|c|c|c|c|c|c|c|c|c|c|c|c|c|c|c|}
\hline \multirow{2}{*}{$\begin{array}{l}\text { Planning } \\
\text { decision }\end{array}$} & \multicolumn{2}{|c|}{$\begin{array}{c}\text { At } \\
\text { Home }\end{array}$} & \multicolumn{2}{|c|}{$\begin{array}{l}\text { Out-of- } \\
\text { Home }\end{array}$} & \multicolumn{2}{|c|}{ As Planned } & \multicolumn{2}{|c|}{$\begin{array}{l}\text { Modified/ } \\
\text { deleted }\end{array}$} & \multicolumn{2}{|c|}{ Preplanned } & \multicolumn{2}{|c|}{ Spontaneous } & \multicolumn{2}{|c|}{$\begin{array}{l}\text { With } \\
\text { Others* }\end{array}$} & \multicolumn{2}{|c|}{ Alone* } \\
\hline & total & $\%$ & total & $\%$ & total & $\%$ & total & $\%$ & total & $\%$ & total & $\%$ & total & $\%$ & total & $\%$ \\
\hline Hobbies & 160 & 70.8 & 66 & 29.2 & 184 & 81.4 & 42 & 18.6 & 128 & 56.6 & 98 & 43.4 & 64 & 28.3 & 162 & 71.7 \\
\hline $\begin{array}{l}\text { Exercise or active } \\
\text { sports }\end{array}$ & 157 & 18.6 & 689 & 81.4 & 685 & 81.0 & 161 & 19.0 & 514 & 60.8 & 332 & 39.2 & 295 & 34.9 & 551 & 65.1 \\
\hline $\begin{array}{l}\text { Spectator Events/ } \\
\text { Theatre }\end{array}$ & 7 & 4.2 & 159 & 95.8 & 129 & 77.7 & 37 & 22.3 & 98 & 59.0 & 68 & 41.0 & 129 & 77.7 & 37 & 22.3 \\
\hline Playing/parks & 53 & 50.0 & 53 & 4.4 & 83 & 78.3 & 23 & 21.7 & 55 & 51.9 & 51 & 48.1 & 53 & 50.0 & 53 & 50.0 \\
\hline $\begin{array}{l}\text { Regular TV } \\
\text { programs }\end{array}$ & 2200 & 99.0 & 22 & 1.8 & 1912 & 86.0 & 310 & 14.0 & 1235 & 55.6 & 987 & 44.4 & 946 & 42.6 & 1276 & 57.4 \\
\hline Unspecific TV & 504 & 98.8 & 6 & 0.5 & 459 & 90.0 & 51 & 10.0 & 175 & 34.3 & 335 & 65.7 & 196 & 38.4 & 314 & 61.6 \\
\hline Watching video & 245 & 97.2 & 7 & 0.6 & 237 & 94.0 & 15 & 6.0 & 102 & 40.5 & 150 & 59.5 & 166 & 65.9 & 86 & 34.1 \\
\hline $\begin{array}{l}\text { Relaxing/napping/ } \\
\text { reading }\end{array}$ & 2608 & 98.0 & 53 & 2.0 & 2221 & 83.5 & 440 & 16.5 & 1231 & 46.3 & 1430 & 53.7 & 673 & 25.3 & 1988 & 74.7 \\
\hline Email/internet & 728 & 99.2 & 6 & 0.5 & 648 & 88.3 & 86 & 11.7 & 303 & 41.3 & 431 & 58.7 & 59 & 8.0 & 675 & 92.0 \\
\hline $\begin{array}{l}\text { Other recreation/ } \\
\text { entertainment }\end{array}$ & 101 & 39.6 & 154 & 60.4 & 224 & 87.8 & 31 & 12.2 & 154 & 60.4 & 101 & 39.6 & 151 & 59.2 & 104 & 40.8 \\
\hline Total & 6763 & & 1215 & & 6782 & & 1196 & & 3995 & & 3983 & & 2732 & & 5246 & \\
\hline
\end{tabular}

$\left(^{*}\right)$ Data about the "with whom" planning decision was only available for the following activities: Basic Needs out-of-home, Household Obligations out-of-home, and Recration/Entertainment and Social activities

\section{ANALYSIS AND RESULTS}

The objective of this analysis is to develop a set of models, one for each activity type, that describe differences in scheduling decisions. First, for aggregate activity types, three planning decisions are examined including location, time planning horizon and modification or deletion of activities during the scheduling process. Models for all aggregate activity types have been developed, but in this paper only models for basic needs, drop-off/pick-up, recreation/entertainment and social activities are included. These models display the most significant dissimilarities in the scheduling process. Then, the "with whom" planning decision is added in an in-depth analysis to confirm variations in the scheduling process among several sub-types of recreational/entertainment activities including exercise or active sports, regular TV programs, relaxing/napping/reading and email/internet. In the first analysis, the incidence of schedule decisions is described by a 3-binary element schedule decision vector, where the three elements represent whether the activity is carried out at home or out-of-home, spontaneously planned or preplanned, and modified/deleted prior to its execution or executed as planned, respectively. In the second analysis, the incidence of schedule decisions is described by a 4-binary element schedule decision vector, in which the additional element represents whether the activity is carried out alone or with other(s).

Using these characterizations of schedule decisions, we explore how the decisions are affected by a number of factors including characteristics of the household, features of the activities and socio-demographic characteristics of the individual respondent. The focus is on detecting different activity scheduling mechanisms for different activity types. The incidence of 
scheduling decisions is modeled using a multivariate probit (MVP) model. The MVP is a popular class of models particularly suitable for the analysis of correlated binary data (Greene, 2003). In this class of models, the response is multivariate, correlated and discrete. Generally speaking, the MVP model assumes that given a set of explanatory variables the multivariate response is an indicator of the event that some unobserved latent continuous variable exceeds a threshold, which can be taken to be zero, without loss of generality. The latent continuous variable is assumed to arise from a multivariate normal distribution. The characteristics of this model fit well in this case. MVP models were used by the authors in similar research with different datasets and we obtained coherent results. The appeal of the probit model is that it relaxes the independence of the irrelevant alternatives (IIA) property assumed by the logit model. Model specification and results are discussed in more detail below.

\subsection{Multivariate probit model of the incidence of schedule decision}

The proposed model concentrates on describing the incidence of schedule decisions of different types. Thus, in the first analysis our interest is focused on whether or not the activity is planned to be carried out at home or out-of home, if the activity is preplanned or it is spontaneous, and whether or not the activity is modified or deleted prior to its execution during the scheduling process. In the second analysis we also included whether or not the activity is planned to be carried out with other(s). Each element in the schedule decision vector is recoded as a $0 / 1$ dummy according to whether or not the corresponding schedule decision was made. This recoding of the schedule modification vector results in a dependent variable that has $2^{3}=8$ distinct states in the first analysis, and $2^{4}=16$ distinct states in the second analysis.

We assume that the unobservable propensity of an individual to make each of these scheduling decisions is systematically related to a set of explanatory variables, via a linear model. Corresponding to these underlying unobservables are the actual observations of whether or not decisions are in fact made. Thus we have, for each planned activity in the first analysis:

$$
\begin{aligned}
& P A H=\beta_{1} X+\varepsilon_{1} \quad \text { if } A T H O M E=1, \quad P A H=0 \quad \text { if } \text { ATHOME }=0 \\
& P P A=\beta_{2} Y+\varepsilon_{2} \quad \text { if PREPLAN }=1, \quad P P A=0 \quad \text { if PREPLAN }=0 \\
& P A P=\beta_{3} Z+\varepsilon_{3} \quad \text { if } A S P L A N N E D=1, \quad P A P=0 \quad \text { if ASPLANNED }=0
\end{aligned}
$$

Where:

$P A H=$ unobservable propensity to realize activities at home,

$P P A=$ unobservable propensity to plan activities days/weeks/months in advance or to consider them as routine activities,

$P A P=$ unobservable propensity to realize activities as planned during the scheduling process.

In the second analysis we add: 
$P W O=\beta_{4} W+\varepsilon_{4} \quad$ if WITHOTHE $=1, \quad P W O=0 \quad$ if WITHOTHE $=0$

Where:

$P W O=$ unobservable propensity to realize activities with other(s),

The quantities ATHOME, PREPLAN, ASPLANNED and WITHOTHE are discrete $(0,1)$ variables indicating whether the activity is out-of home/at home, if the activity is spontaneous/preplanned, if the activity is modified or deleted/executed as planned, and the absence/presence of companion(s) during the activity, respectively. The quantities $W, X, Y$ and $Z$ are vectors of (potentially identical) exogenous variables and $\beta_{i}(i=1, \ldots, 3)$ (in the second analysis: $\left.\beta_{i}(i=1, \ldots, 4)\right)$ are vectors of estimable parameters associated with the exogenous influences on the incidence of schedule decisions. The correlated error terms $\varepsilon_{i}$ $(i=1, \ldots, 3)$ (in the second analysis: $\left.\varepsilon_{i}(i=1, \ldots, 4)\right)$ are assumed to be drawn from a multivariate normal distribution with mean 0 and covariance matrix $\Sigma$. Since the observed data contain no information regarding the magnitude of the underlying propensities, the diagonal elements of $\boldsymbol{\Sigma}$ are normalized to unity; the off-diagonal elements of $\boldsymbol{\Sigma}$ enable the model to accommodate unobserved endogenous effects across the three (four) equations.

These multivariate probit (MVP) systems are simultaneously estimated using weighted leastsquare with mean and variance correction estimator (WLSMV). The WLSMV is robust against violation of multivariate normality (Greene, 2003)

The model specifications are developed by testing the significance of the available socioeconomic variables of the respondents' households, several characteristics of the individuals and a number of attributes of the activities implicated in the scheduling decision process (Table 3). Limdep v.4.0.1 was used to design the MVP models. We selected variables to be included in each model considering their importance outlined in previous research. Then we tested other variables to check their significance. Multicollinearity was easily detected when a new variable entered in the model was found to be statistically significant while one or more other variables already in the model lost their significance. Non-significant variables were not included in the model specification, because they often display non-structured variation, i.e. noise. Their removal will result in a more stable and robust model. Usually the prediction error decreases as well.

Different specifications of the covariance matrix are defined to test the existence of endogeneity among the dependent variables, which are defined in Table 4. 
TABLE 3 Sample Mean and Standard Deviations for Explanatory Variables

\begin{tabular}{|c|c|c|c|}
\hline Variable & Definition & Mean & $\begin{array}{l}\text { Std. } \\
\text { Dev. }\end{array}$ \\
\hline \multicolumn{4}{|l|}{$\begin{array}{l}\text { Household } \\
\text { characteristics }\end{array}$} \\
\hline H_1nochildteen & $\begin{array}{l}\text { Reference category: 1-adult household without children nor } \\
\text { teens }\end{array}$ & & \\
\hline H_1childteen & $\begin{array}{l}1 \text { if presence of children or children+teens in } 1 \text {-adult } \\
\text { households, } 0 \text { otherwise }\end{array}$ & 0.033 & 0.178 \\
\hline $\begin{array}{l}\text { H_1 teen } \\
\text { H_2nochildteen }\end{array}$ & $\begin{array}{l}1 \text { if presence of teens in } 1 \text {-adult households, } 0 \text { otherwise } \\
1 \text { if } 2 \text {-adult household without children nor teens }\end{array}$ & 0.026 & 0.157 \\
\hline & 1 if presence of children or children+teens in 2 -adult & 0.347 & 0.476 \\
\hline 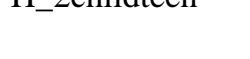 & households, 0 otherwise & 0.272 & 0.445 \\
\hline H_2teen & 1 if presence of teens in 2 -adult households, 0 otherwise & 0.087 & 0.282 \\
\hline H_size & Total number of household members & 2.963 & 1.454 \\
\hline H_kids & Number of kids in household & 0.598 & 1.050 \\
\hline H_teens & Number of teenagers in household & 0.188 & 0.479 \\
\hline H_Adlts & Number of adults in household & 2.162 & 0.963 \\
\hline H_Othrs & Number of other members in household & 0.015 & 0.152 \\
\hline H_Autos & Number of cars in household & 1.494 & 0.602 \\
\hline H_Dsingd & Reference category: single-detached house & & \\
\hline H_Dsemid & 1 if semi-detached house, 0 otherwise & 0.180 & 0.384 \\
\hline H_Dtownh & 1 if Row house/Town house, 0 otherwise & 0.057 & 0.232 \\
\hline H_Dapardet & 1 if Apartment in a detached duplex, 0 otherwise & 0.008 & 0.090 \\
\hline H_Daparbui5 & $\begin{array}{l}1 \text { if Apartment in a building with FEWER than } 5 \text { stories, } 0 \\
\text { otherwise }\end{array}$ & 0.051 & 0.221 \\
\hline H_Daparbui6 & $\begin{array}{l}1 \text { if Apartment in a building with MORE than } 5 \text { stories, } 0 \\
\text { otherwise }\end{array}$ & 0.066 & 0.250 \\
\hline H_Dother & 1 if Other single-attached house, 0 otherwise & 0.001 & 0.035 \\
\hline H_OwnRnt & 1 if house is owned, 0 otherwise & 0.793 & 0.405 \\
\hline H_ResDur & Residential duration in house (years) & 9.715 & 9.082 \\
\hline H_CitDur & Residential duration in city (years) & 18.200 & 14.965 \\
\hline H_RegDur & Residential duration in region (years) & 24.429 & 16.272 \\
\hline \multicolumn{4}{|l|}{$\begin{array}{l}\text { Individual } \\
\text { characteristics }\end{array}$} \\
\hline I_Rmalehead & Reference category: male head of household & & \\
\hline I_Rfemhead & 1 if female head of household, 0 otherwise & 0.480 & 0.500 \\
\hline I_Rson & 1 if son, 0 otherwise & 0.043 & 0.203 \\
\hline I_Rdau & 1 if daughter, 0 otherwise & 0.064 & 0.245 \\
\hline I_Roth & 1 if other, 0 otherwise & 0.014 & 0.117 \\
\hline I_Gender & 1 if male, 0 if female & 0.448 & 0.497 \\
\hline I_Tsingadu & Reference category: Single adult in household & & \\
\hline I_Tadupartn & 1 if Adult in partnership in household, 0 otherwise & 0.643 & 0.479 \\
\hline I_Tteen & 1 if Teen in household, 0 otherwise & 0.032 & 0.176 \\
\hline I_Taduother & 1 if Other adult in household, 0 otherwise & 0.017 & 0.129 \\
\hline I_Taduchild & 1 if Adult child in household, 0 otherwise & 0.070 & 0.254 \\
\hline I_Autos & Number of cars & 1.557 & 0.588 \\
\hline I_Age & Age of respondent & 43.557 & 14.272 \\
\hline I_Income & Annual income of respondent & 45258.429 & 36552.300 \\
\hline I_Licens & 1 if respondent has driver license, 0 otherwise & 0.907 & 0.291 \\
\hline I_Efulltime & Reference category: Employed Full Time & & \\
\hline I_Eparttime & 1 if Employed Part Time, 0 otherwise & 0.124 & 0.329 \\
\hline I_Ehome & 1 if Homemaker, 0 otherwise & 0.060 & 0.237 \\
\hline I_Enotemp & 1 if Not Employed or Retired, 0 otherwise & 0.195 & 0.396 \\
\hline I_Ewo & 1 if Work at Home, 0 otherwise & 0.051 & 0.221 \\
\hline I_Sfulltime & Reference category: Full Time Student & & \\
\hline
\end{tabular}




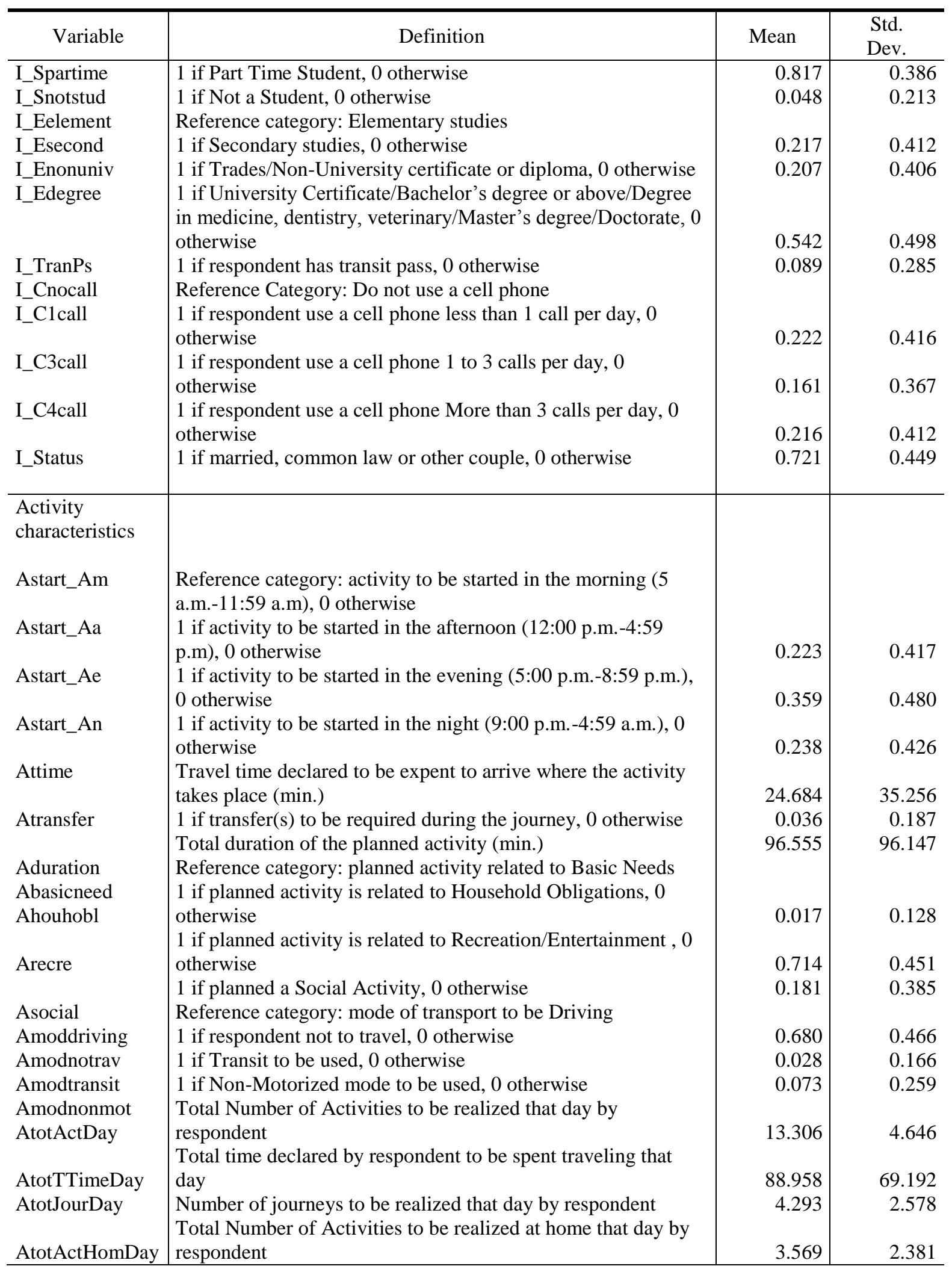


TABLE 4 Sample Mean and Standard Deviations for Scheduling Decisions

\begin{tabular}{l|l|r|r}
\hline \multicolumn{1}{c|}{ Variable } & \multicolumn{1}{c|}{ Definition } & Mean & $\begin{array}{c}\text { Std. } \\
\text { Dev. }\end{array}$ \\
\hline ASPLANNED & $\begin{array}{l}1 \text { if planned activity not modified nor deleted prior to its } \\
\text { execution, } 0 \text { otherwise }\end{array}$ & 0.865 & 0.342 \\
ATHOME & 1 if activity to be taken place at home, 0 otherwise & 0.502 & 0.469 \\
WITHOTHE & 1 if activity to be realized with other(s), 0 otherwise & 0.500 \\
PREPLAN & $\begin{array}{l}1 \text { if activity is planned day(s)/week(s)/month(s) before the date } \\
\text { of its execution } \text { or it is a routine activity, } 0 \text { otherwise }\end{array}$ & 0.419 & 0.493 \\
\hline
\end{tabular}

The estimated model parameters, correlation matrix and goodness-of-fit indices are summarized in Tables 5 and 6 . The results include for each explanatory variable: coefficient estimates, the ratio of the estimates to their standard errors, and the probability of obtaining a greater F statistic than that observed if the null hypothesis is true. The Est./S.E. column can be used to evaluate significance. If the absolute value of the number in this column is greater than 1.96 the estimate can be interpreted as significant at the 0.05 level. Positive coefficients indicate an increased probability of a particular scheduling decision.

\subsection{Analysis for aggregate classification of activity types}

Eight models were developed to analyze differences in how respondents make decisions during the activity scheduling process depending on the aggregate classification of activity type. In this paper only four models are presented which include the more statistically significant results obtained for activity types that have large sample sizes. The results are presented in Table 5.

Global differences for each activity type are presented first. A detailed analysis follows, which focuses on those parameters that have different signs between models. Both are directly related to differences about how planning decisions are taken for each activity type. Finally, the modeling approach used allows us to study correlation among planning decisions, and how those correlations differ between activity types.

\subsubsection{Estimation results: global differences}

Significant differences are found in modeling results for each activity type and each planning decision. The location decision (ATHOME) for basic needs activities is explained in the model by five household characteristics and four features of the observed activities. Respondents in 1 or 2 -adult households with children and/or teens are more likely to plan basic needs activities at home than those in 1-adult household without children or teens. 
The more teens in the household, the more likely it is that the basic needs activity is planned to be carried out at home. Arguably the presence of teens in the household requires adults to plan more attention to them.

Respondents who live in town houses have a higher tendency to plan basic needs activities at home compared with respondents who live in a single-detached houses.

The longer the respondent has lived in the region the more likely is that basic needs are planned to be carry out at home. This indicates that long-established families, often the elderly, are more home-oriented.

If a basic needs activity does not require travel it is highly likely to be at home, indicating that people tend to report consecutive basic needs activities at home. If it involves a transit trip, it is more likely to be planned at home compared with activities involving a drive trip. But if the respondent plans to use a non-motorized transportation mode, then it is less likely that the basic needs activity will be carried out at home. It may be easier to plan out-of-home basic needs activities when destination can be reach walking or biking.

The larger the number of activities planned per day, the less likely that basic needs activities are planned at home. In this case it is very likely that people are carrying out several activities out-of-home, so basic needs are being fit in as part of a tour of consecutive out-of-home activities.

The location decision model specification is similar for recreation/entertainment activities, for which location is mainly explained by household characteristics and features of the activities. It is interesting that for this model, the later the activity start time, the more likely it is to be planned at home. Shorter duration activities are more likely to be done at home as well. Household structure variables are somewhat mixed, but do indicate that households with children are more likely to stay at home, and that the number of teenagers has a further positive influence on staying home.

The model specifications for drop-off/pick-up and social models are different in the sense that they also include attributes of the individual respondents. These models are based on fewer observations of at-home activities (especially the drop-off/pick-up model) which probably explains the smaller number of statistically significant variables. 
TABLE 5 Mulivariate Probit Coefficient Estimates and Correlation Matrix. Aggregate Analysis

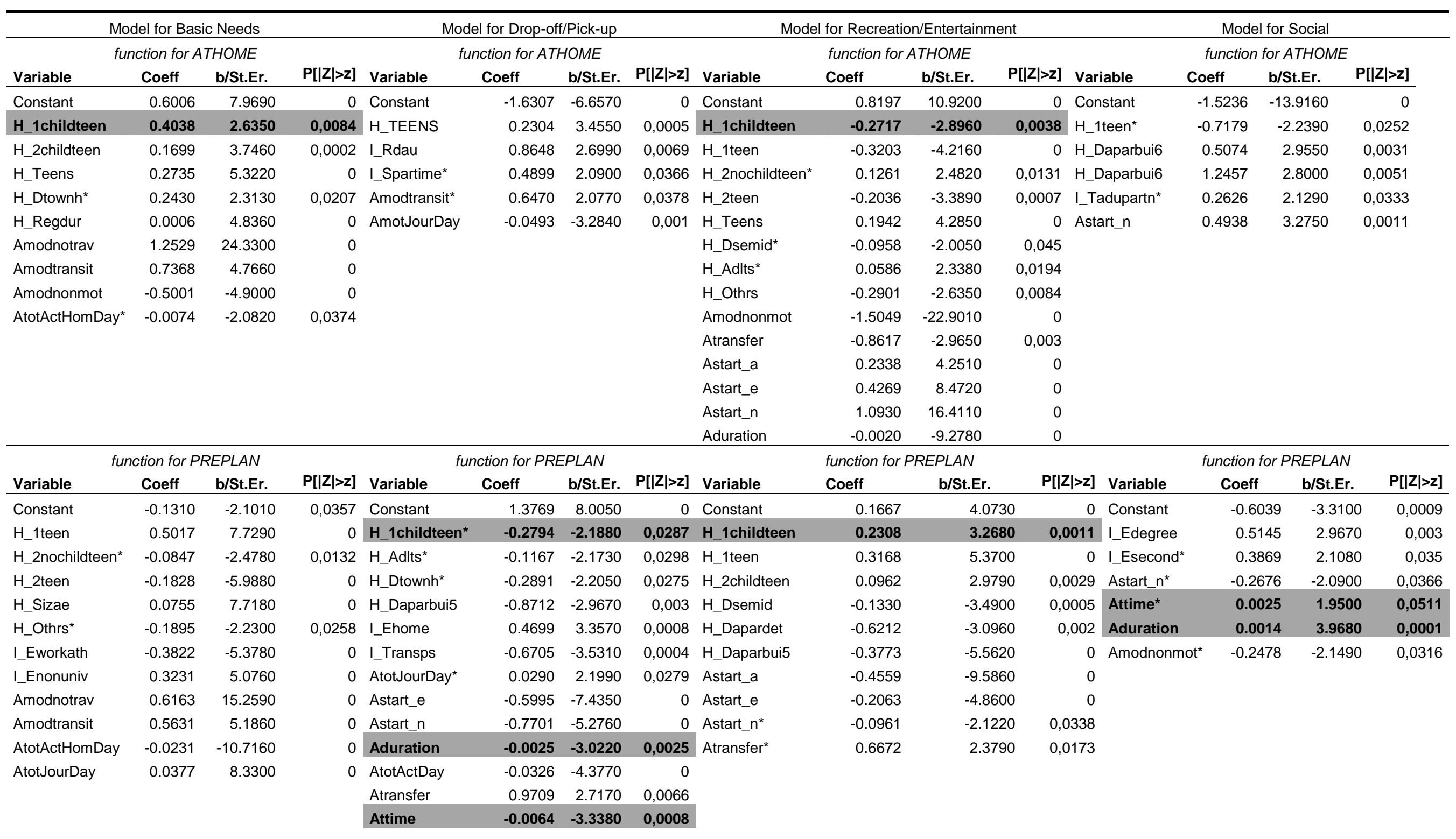




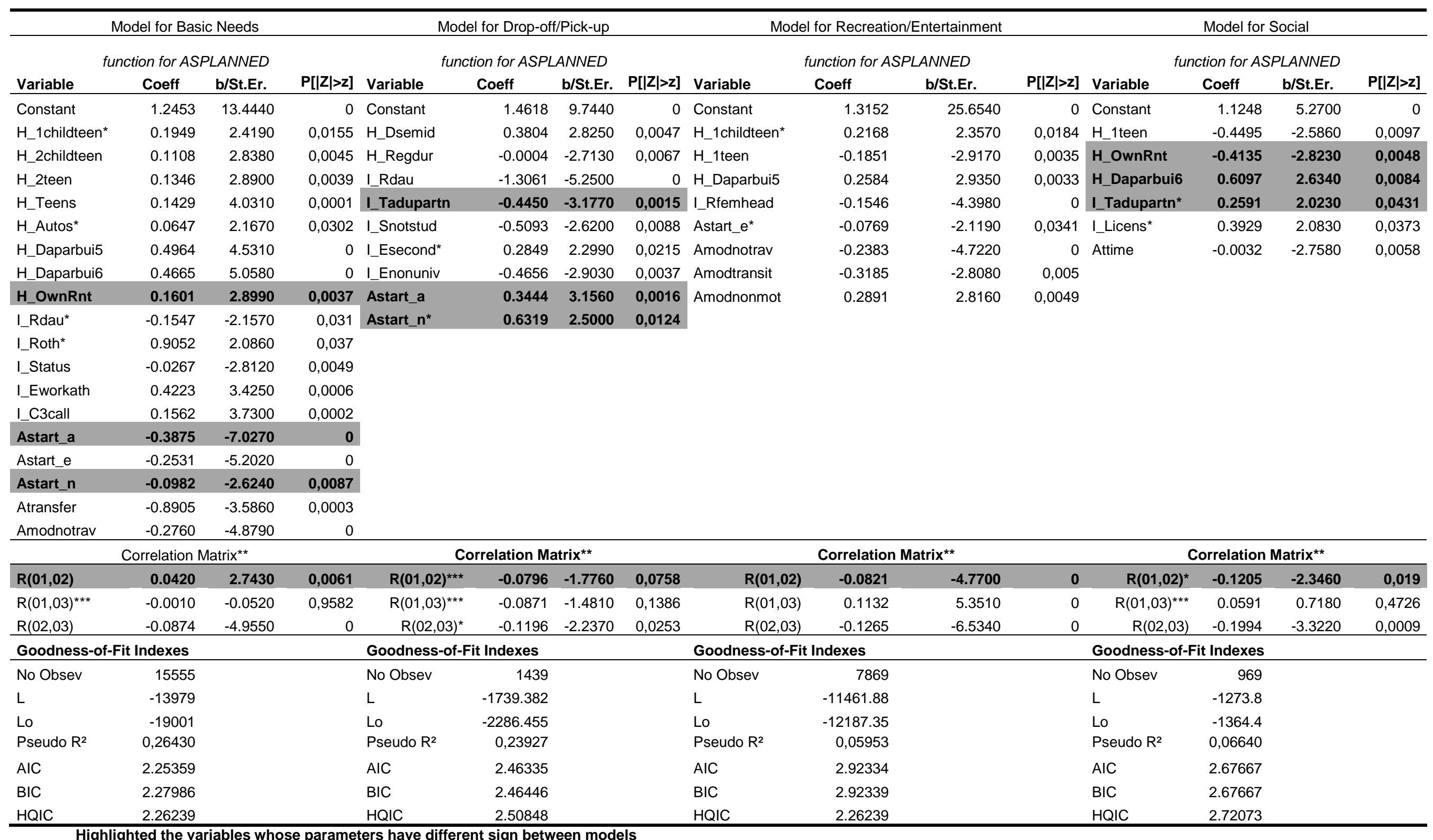

Highlighted the variables whose parameters have different sign between models

$* X^{2}$ test significant at 0.05 level; all others significant at 0.01 level (except for the correlation matrix coefficients, which are significant over 0.05 level if they are marked with ${ }^{\star \star *}$ )

$(* *) 01$ = ATHOME, 02 = PREPLAN, 03 = ASPLANNED 
It is noted that we did not begin the modeling exercise with very strong a priori expectations about many of the relationships in this set of models, however, none of the implied behavioral relationships appear to be implausible. For the sake of brevity, the results of other models are not described in as much detail.

Similar results are found to explain the planning time horizon (PREPLAN): basic needs and recreation/entertainment activities are mainly explained by household characteristics and features of the activities. In this case, drop-off/pick-up activities are only related to household and individual characteristics. The planning time horizon of social activities is explained by individual characteristics and features of the activities.

Finally, whether or not the planned activity is executed as planned without modification or deletion (ASPLANNED) is mainly explained by household characteristics and features of the activities for recreation/entertainment activities. Individual characteristics are more important to explain this planning decision if it is a drop-off/pick-up activity. Social activities are more explained by household and individual characteristics. Regarding basic needs, a combination of variables are significant in explaining this decision.

Planning of recreation/entertainment activities is mainly related to household and activity variables. Almost no individual variable is significant in this model. As many activities of this type are planned to be carried out with others, it is logical that the type and number of family members are influencing this scheduling decision. Family members are usually the companions in recreation/entertainment activities, or are conditioning where the activity is planned or whether it is modified or not prior to its execution.

Planning of basic needs activities is explained by household and activity variables and to a lesser extent by individual variables. The importance of household characteristics in planning this type of activity is related to the fact that many are planned to be carried out at home, so again the type and number of family members are influencing this scheduling decision.

In contrast, planning of social activities is related to individual and activity variables, and to a lesser extent to household characteristics. This indicates that many social activities are planned to be carried out with non-family members. This explains the lower importance of household characteristics in this scheduling decision. Finally, planning drop-off/pick-up activities depends on a combination of explanatory variables.

\subsubsection{Estimation results: differences in parameter signs}

Different types of activities are planned in different ways. First, it is clear from Table 5 that different model specifications result for each of the activity types. In each of the models, different variables enter significantly with respect to location, when the activity is planned and whether activities are executed as planned. For the sake of brevity we focus our analysis on those parameters that are significant in corresponding models for different activity types, but exhibit different signs (shaded cells in Table 5). We consider these to be the most important behavioural differences that arise from this analysis.

Planning decisions related to activity location are different for basic needs and recreation/entertainment activities in 1-adults households with children or children+teens. Basic needs related activities are more likely to be planned at home while 
recreation/entertainment related activities are more likely to be planned out-of-home for these respondents. As explained before, it is very reasonable that the presence of teens obliges adults to pay more attention to them at home, but the teenage years are perhaps the age in which people tend to carry out most of their leisure activities out-of-home, influencing the rest of the family members.

Respondents decide at different times to carry out drop-off/pick-up, recreation/entertainment and social activities. Those living in 1-adult households with children or children+teens are more likely to plan drop-off/pick-up activities on the same day or spontaneously. But recreation/entertainment activities are more likely to be preplanned for such respondents. So planning the latter type of activities requires more coordination among family members than drop-off/pick-up.

High duration drop-off/pick-up activities are more likely to be planned on the same day or spontaneously as well. On the contrary, high duration social activities tend to be preplanned. The longer the trip duration to the drop-off/pick-up activity the more likely it is planned on the same day or spontaneously. However, in similar circumstances social activities are more likely to be preplanned. These results may be explained because social activities require more coordination among participants as well, regardless of the duration of the activity or the associated travel.

Finally, the extent to which activities are executed as planned is different for basic needs, drop-off/pick-up and social activities. Respondents who own their house are more likely to execute basic needs activities as planned. However, home owners tend to modify or delete their drop-off/pick-up activities prior to their execution. Perhaps because planning dropoff/pick-up activities always relies on another person and most of basic needs are carried out alone. Adults in partnership are more likely to modify/delete drop-off/pick-up activities than single adults, quite possibly because the responsibilities can be transferred to the partner. Such respondents, however, present a higher tendency to execute social activities as planned, potentially because the partner can take on other unexpected conflicting obligations that arise.

Basic needs activities starting in the afternoon or at night are more likely to be modified or deleted prior to their execution than the same type of activity starting in the morning. We believe this is because the morning tends to be more routine and future potentially conflicting activities arise at this time of day. On the other hand, drop-off/pick-up activities starting in the afternoon or at night have a higher tendency to be executed as planned than their morning counterparts. Drop-off/pick-up activities at night are planned more spontaneously and this results in less opportunity for modification, whereas drop-off/pick-up in the morning is preplanned and can be affected by later modification.

\subsubsection{Estimation results: correlation among planning decisions}

There is a significant positive correlation in the error terms between planning basic needs activities at home and planning them in advance or consider them as routine activities. This is very reasonable: most basic needs activities that are planned to be carried out at home are routine (sleeping, having breakfast, etc.). However, the correlation between these two planning decisions is negative for drop-off/pick-up, recreation/entertainment or social activities, indicating that if they are planned to be carried out at home, they are more likely to be spontaneous or planned on the same day. This indicates that the home is available as a 
venue for such activities without the necessary preplanning associated with accessing other facilities or other people's homes. Error term correlations between location and activity rescheduling are generally less significant. However, there are strong, consistent and sensible negative correlations between preplanning and activity rescheduling. The earlier an activity is planned, the more opportunity there is to reschedule that activity.

\subsection{Analysis for disaggregate classification of recreation/entertainment activities}

Four models were developed using disaggregate data for the following subtypes of recreation/entertainment activities: exercise or active sports, regular TV programs, relaxing/napping/reading and email/internet. These models are presented in Table 6. In addition to the location, planning horizon and whether activities were executed as planned, "with whom" information was also used as a dependent variable because this data was collected without any misunderstanding for recreation/entertainment activities.

Similar to the previous analysis, global differences for each activity sub-type are presented first. Then, a detailed analysis follows, which focuses on those parameters that have different signs between models. Finally, correlations among planning decisions are presented.

\subsubsection{Estimation results: global differences}

Again, significant differences in model results are apparent for each activity sub-type and each planning decision. Decisions of whether to engage in relaxing/napping/reading activities with other people (WITHOTHE) are mostly explained by household characteristics. Planning to watch regular TV programs depends on both household and individual characteristics. A combination of household, individual and activity attributes is significant in models for exercise or active sports and email/internet related activities. These differences could be explained considering that planning relaxing/napping/reading activities to be carried out alone or with companions depends to a greater extent on the number and type of members in the household. On the other hand, the rest of the subtypes of recreation/entertainment activities rely more on the individual's preferences, hobbies, etc.

Whether or not the activity is executed as planned depends mainly on household characteristics if the activity is exercise/active sports or email/internet. Other explanatory variables also influence this decision, but are less important. In the case of watching regular TV programs, individual and activity characteristics affect the decision of modifying/deleting the planned activity prior to its execution. Most activities related to watching regular TV programs are planned to be carried out at home. Plausibly other factors related to the activity (timing) or the individual should explain this scheduling decision. For relaxing/napping/reading activities, this planning decision is explained mainly by household and activity characteristics. Again, number and type of family member may influence scheduling decisions related to relaxing/napping/reading activities. As suggested before, the presence of children may alter any planning related specially with at-home activities.

Relatively few variables are statistically significant to explain location decisions and the time horizon of planning. This is probably a result of the smaller sample sizes that are observed when dealing with detailed activity subtypes. 


\subsubsection{Estimation results: differences in parameter signs}

The models in Table 6 show that different sub-types of recreation/entertainment activities are planned in different ways, as indicated by different parameter signs on the same explanatory variable. These differences are indicated with the shaded cells in Table 6 .

Decisions of whether activities are done with others are different for relaxing/napping/reading activities and for mail/internet activities. The parameter signs are opposite for the variable indicating a 2-adult household without children/teens. For respondents in such households, relaxing/napping/reading activities are more likely to be planned with others, while mail/internet activities have a higher tendency to be planned alone. Not surprisingly, 2-adult households do not find companionship by spending their time on email or internet, whereas they do for relaxing/napping/reading activities.

Respondents in households with a high number of adults plan with different time horizons relaxing/napping/reading activities and e-mail/internet related activities. The former are more likely to be planned on the same day or spontaneously, but these respondents present a higher tendency to preplan e-mail/internet related activities. The latter finding may be related to the increasing participation in electronic social networks, which frequently requires internet activities to be planned in advance with other network members. However, it is possible that household members are sharing the use of a computer, which would also require preplanning.

Whether activities are executed as planned varies among the four recreation/entertainment sub-types considered. Relaxing/napping/reading activities in the evening are more likely to be executed as planned than those in the morning. But other types of recreation/entertainment activities in the evening present a higher tendency to be modified than those in the morning. This could be explained considering that relaxing/napping/reading activities tend to be planned on the same day or spontaneously as explained previously. So their planning can be adapted to the activities and travels already done earlier in the day, requiring no modification prior to their execution. On the contrary, the rest of the recreation/entertainment activities tend to be preplanned more than relaxing/napping/reading, and it is more likely they have to be modified or deleted before execution because of unexpected changes in earlier activities and travels.

Longer duration relaxing/napping/reading activities are more likely to be modified or deleted prior to their execution. On the other hand, the longer the duration of the exercise or active sports, the more likely it is executed as planned. Again, we have other important finding that confirms the main hypothesis of this study: different activity types present different scheduling processes. Longer duration of activities is usually associated with more flexibility (Auld et al, 2008). But a deeper analysis of subtypes of recreational/entertainment activities show us that long exercise or active sports tend to be executed as planned, because of a commitment to a team or a training schedule. 
TABLE 6 Mulivariate Probit Coefficient Estimates and Correlation Matrix. Disaggregate Analysis

\begin{tabular}{|c|c|c|c|c|c|c|c|c|c|c|c|c|c|c|c|}
\hline \multicolumn{4}{|c|}{ Model for Exercise or active sports } & \multicolumn{4}{|c|}{ Model for Regular TV programs } & \multicolumn{4}{|c|}{ Model for Relaxing/napping/reading } & \multicolumn{4}{|c|}{ Model for Email/internet } \\
\hline \multicolumn{4}{|c|}{ function for ATHOME } & \multicolumn{4}{|c|}{ function for ATHOME } & \multicolumn{4}{|c|}{ function for ATHOME } & \multicolumn{4}{|c|}{ function for ATHOME } \\
\hline Variable & Coeff & b/St.Er. & $\mathbf{P}[|\mathbf{Z}|>\mathbf{Z}]$ & Variable & Coeff & b/St.Er. & $\mathbf{P}[|\mathrm{Z}|>\mathbf{Z}]$ & Variable & Coeff & b/St.Er. & $\mathbf{P}[|\mathrm{Z}|>\mathrm{Z}]$ & Variable & Coeff & b/St.Er. & b/St.Er. \\
\hline Constant & -1.1267 & -4.218 & 0 & Constant & 2.6738 & 16.199 & 0 & Constant & 2.8992 & 7.974 & 0 & Constant & 1.7161 & 1.191 & 1,191 \\
\hline H_2teen* & -1.0496 & -2.398 & 0,0165 & H_Dsemid* & -0.7856 & -2.532 & 0,0113 & H_2nochildteen & 0.5086 & 2.325 & 0,0201 & Amodtransit* & 1.1546 & 2.163 & 2,163 \\
\hline H_Size & -0.2245 & -2.604 & 0,0092 & H_Daparbui6 & -1.0088 & -3.098 & 0,002 & H_Adlts & -0.2646 & -3.382 & 0,0007 & & & & \\
\hline \multirow[t]{3}{*}{ I_Tadupartn } & 0.9479 & 3.194 & 0,0014 & I_Rdau* & -0.8422 & -1.967 & 0,0492 & I_Tadupartn* & 0.4536 & 2.339 & 0,0193 & & & & \\
\hline & & & & Amodnonmot & -1.0149 & -2.574 & 0,0101 & Aduration* & -0.003 & -2.42 & 0,0155 & & & & \\
\hline & & & & & & & & Attime & -0.0917 & -3.672 & 0,0002 & & & & \\
\hline \multicolumn{4}{|c|}{ function for PREPLAN } & \multicolumn{4}{|c|}{ function for PREPLAN } & \multicolumn{4}{|c|}{ function for PREPLAN } & \multicolumn{4}{|c|}{ function for PREPLAN } \\
\hline Variable & Coeff & b/St.Er. & $\mathrm{P}[|\mathrm{Z}|>\mathrm{Z}]$ & Variable & Coeff & b/St.Er. & $\mathrm{P}[|\mathrm{Z}|>\mathbf{Z}]$ & Variable & Coeff & b/St.Er. & $\mathrm{P}[|\mathrm{Z}|>\mathrm{Z}]$ & Variable & Coeff & b/St.Er. & $\mathrm{P}[|\mathrm{Z}|>\mathrm{z}]$ \\
\hline Constant & 1.5973 & 5.333 & 0 & Constan & 0.9585 & 5.356 & 0 & Constant & 0.4388 & 2.307 & 0,021 & Constant & 2.3393 & 4.604 & 0 \\
\hline H_2teen & -0.7759 & -3.757 & 0,0002 & H_Othrs* & -1.2473 & -2.402 & 0,0163 & H_1teen & -0.3295 & -3.487 & 0,0005 & H_Adlts & -0.2694 & -2.169 & 0,0301 \\
\hline I_Rfemhead* & -0.3411 & -2.049 & 0,0405 & I_C2call & -0.3332 & -2.878 & 0,004 & H_Adlts* & 0.1152 & 2.162 & 0,0306 & & & & \\
\hline I_Age & -0.018 & -3.325 & 0,0009 & I_C3call* & -0.2643 & -2.05 & 0,0403 & H_Autos* & 0.1808 & 2.304 & 0,0212 & & & & \\
\hline \multirow[t]{3}{*}{ AtotActDay } & 0.0696 & 7.16 & 0 & AtotActDay & 0.0301 & 2.245 & 0,0248 & I_Snotstud* & 0.501 & 2.165 & 0,0304 & & & & \\
\hline & & & & & & & & AtotActDay & 0.0423 & 3.926 & 0,0001 & & & & \\
\hline & & & & & & & & AtotTTimeDay & -0.0914 & -4.595 & 0 & & & & \\
\hline \multicolumn{4}{|c|}{ function for ASPLANNED } & \multicolumn{4}{|c|}{ function for ASPLANNED } & \multicolumn{4}{|c|}{ function for ASPLANNED } & \multicolumn{4}{|c|}{ function for ASPLANNED } \\
\hline Variable & Coeff & b/St.Er. & $\mathrm{P}[|\mathrm{Z}|>\mathbf{Z}]$ & Variable & Coeff & b/St.Er. & $\mathrm{P}[|\mathrm{Z}|>\mathrm{Z}]$ & Variable & Coeff & b/St.Er. & $\mathrm{P}[|\mathrm{Z}|>\mathrm{Z}]$ & Variable & Coeff & b/St.Er. & $\mathrm{P}[|\mathrm{Z}|>\mathrm{z}]$ \\
\hline Constant & 0.7906 & 3.178 & 0,0015 & Constant & -0.6793 & -2.417 & 0,0156 & Constant & 0.1513 & 1.097 & 0,2727 & Constant & -1.2016 & -4.557 & 0 \\
\hline H_1childteen & -1.349 & -3.714 & 0,0002 & H_Adlts & 0.136 & 3.375 & 0,0007 & H_1teen & -0.2602 & -3.53 & 0,0004 & H_1teen & 1.2104 & 3.5 & 0,0005 \\
\hline H_2teen & -1.9642 & -3.744 & 0,0002 & I_Status & 0.0749 & 3.719 & 0,0002 & H_Dtownh & -0.4788 & -2.766 & 0,0057 & H_2teen* & 0.5854 & 2.116 & 0,0344 \\
\hline H_Teens & 1.0851 & 2.771 & 0,0056 & I_License & 0.3478 & 2.634 & 0,0084 & I_Rson & -0.576 & -2.571 & 0,0101 & H_Adlts & 0.1851 & 2.188 & 0,0287 \\
\hline H_Dsemid & -0.8818 & -4.179 & 0 & I_Eworkath & -1.1372 & -5.102 & 0 & Astart_e & 0.2166 & 2.857 & 0,0043 & H_Dsemid & -0.7821 & -3.487 & 0,0005 \\
\hline H_Daparbui6 & -1.6872 & -5.366 & 0 & I_Spartime & 0.4333 & 3.621 & 0,0003 & Aduration & -0.0014 & -2.92 & 0,0035 & H_Resdur & 0.0333 & 4.14 & 0 \\
\hline H_Citdur & -0.0153 & -3 & 0,0027 & I_Enonuniv & -0.3452 & -2.952 & 0,0032 & Amodtransit & 0.7629 & 3.896 & 0,0001 & I_Rson & -1.1619 & -3.867 & 0,0001 \\
\hline I_Tteen & -1.9582 & -4.145 & 0 & I_Edegree* & -0.2114 & -2.244 & 0,0249 & AtotActDay & -0.0216 & -2.656 & 0,0079 & I_Eparttime & 0.9416 & 4.358 & 0 \\
\hline I_Status & 0.1146 & 2.601 & 0,0093 & Astart_e $e^{*}$ & -0.1875 & -2.444 & 0,0145 & & & & & Astart_e $e^{*}$ & -0.3267 & -2.019 & 0,0435 \\
\hline I_Transp & -0.7134 & -2.719 & 0,0066 & Amodnotrav & -0.459 & -4.068 & 0 & & & & & & & & \\
\hline Astart_e & -0.5091 & -3.368 & 0,0008 & AtotActDay* & 0.0209 & 2.23 & 0,0258 & & & & & & & & \\
\hline Aduration* & 0.0042 & 2.151 & 0,0315 & AtotTTimeDay* & -0.0014 & -2.103 & 0,0355 & & & & & & & & \\
\hline Amodtransit & -0.4385 & -2.725 & 0,0064 & & & & & & & & & & & & \\
\hline
\end{tabular}




\begin{tabular}{|c|c|c|c|c|c|c|c|c|c|c|c|c|c|c|c|}
\hline \multicolumn{4}{|c|}{ Model for Exercise or active sports } & \multicolumn{4}{|c|}{ Model for Regular TV programs } & \multicolumn{4}{|c|}{ Model for Relaxing/napping/reading } & \multicolumn{4}{|c|}{ Model for Email/internet } \\
\hline \multicolumn{4}{|c|}{ function for WITHOTHE } & \multicolumn{4}{|c|}{ function for WITHOTHE } & \multicolumn{4}{|c|}{ function for WITHOTHE } & \multicolumn{4}{|c|}{ function for WITHOTHE } \\
\hline Variable & Coeff & b/St.Er. & $P[|Z|>Z]$ & Variable & Coeff & b/St.Er. & $\mathrm{P}[|\mathrm{Z}|>\mathrm{Z}]$ & Variable & Coeff & b/St.Er. & $\mathbf{P}[|\mathrm{Z}|>\mathrm{Z}]$ & Variable & Coeff & b/St.Er. & $P[|Z|>Z]$ \\
\hline Constant & -0.0314 & -0.113 & 0,9097 & Constant & -0.8059 & -3.289 & 0,001 & Constant & -0.4291 & -3.016 & 0,0026 & Constant & -1.7694 & -9.152 & 0 \\
\hline H_1childteen* & 0.9854 & 2.171 & 0,0299 & H_2childteen & 0.8568 & 8.846 & 0 & H_1childteen & 1.1481 & 4.491 & 0 & H_2nochildteen & -0.8029 & -3.708 & 0,0002 \\
\hline H_2childteen & 0.3655 & 2.305 & 0,0212 & H_2teen & 0.5399 & 4.567 & 0 & H_2nochildteen & 0.5514 & 4.296 & 0 & I_Tadupartn & 0.9065 & 4.91 & 0 \\
\hline H_Autos & -0.3856 & -3.026 & 0,0025 & H_Adlts & 0.1238 & 3.621 & 0,0003 & H_2childteen & 1.4775 & 7.993 & 0 & I_Esecond ${ }^{*}$ & 0.4663 & 2.291 & 0,0219 \\
\hline I_Tteen & 1.4541 & 3.335 & 0,0009 & H_Othrs & 1.6524 & 2.59 & 0,0096 & H_2teen & 0.8895 & 4.545 & 0 & & & & \\
\hline I_Status & -0.1474 & -3.03 & 0,0024 & I_Rfemhead & 0.2395 & 2.92 & 0,0035 & H_Size & -0.2166 & -4.481 & 0 & & & & \\
\hline I_Enonuniv & 0.4281 & 2.62 & 0,0088 & I_Rson & -0.8678 & -3.265 & 0,0011 & H_Kids ${ }^{*}$ & 0.1422 & 2.046 & 0,0408 & & & & \\
\hline Astart_a & 0.6371 & 3.46 & 0,0005 & I_Age & -0.0092 & -2.569 & 0,0102 & H_Dtownh* & -0.4325 & -2.387 & 0,017 & & & & \\
\hline Astart_e & 0.5336 & 3.218 & 0,0013 & I_License* & 0.2979 & 2.055 & 0,0398 & I_Ehome & 0.5082 & 3.556 & 0,0004 & & & & \\
\hline \multirow[t]{2}{*}{ Astart_n } & 2.0996 & 2.991 & 0,0028 & I_Eworkath & 0.5627 & 2.763 & 0,0057 & Amodnotrav & -0.2829 & -3.235 & 0,0012 & & & & \\
\hline & & & & I_Edegree & 0.2715 & 3.199 & 0,0014 & & & & & & & & \\
\hline \multicolumn{4}{|c|}{ Correlation Matrix ${ }^{\star \star}$} & \multicolumn{4}{|c|}{ Correlation Matrix ${ }^{\star *}$} & \multicolumn{4}{|c|}{ Correlation Matrix $^{\star \star}$} & \multicolumn{4}{|c|}{ Correlation Matrix ${ }^{\star \star}$} \\
\hline $\mathrm{R}(01,02)^{\star}$ & -0.2668 & -2.421 & 0,0155 & $\mathrm{R}(01,02)^{\star \star \star}$ & -0.2746 & -1.812 & 0,07 & $\mathrm{R}(01,02)^{*}$ & -0.3515 & -4.387 & 0 & $\mathrm{R}(01,02)^{\star \star \star}$ & -0.4447 & -0.918 & 0,3587 \\
\hline $\mathrm{R}(01,03)^{\star * *}$ & 0.0384 & 0.48 & 0,631 & $\mathrm{R}(01,03)^{\star * *}$ & 0.0242 & 0.573 & 0,5664 & $\mathrm{R}(01,03)^{\star \star \star}$ & 0.0653 & 1.619 & 0,1054 & $\mathrm{R}(01,03)^{* \star \star}$ & -0.0647 & -0.741 & 0,459 \\
\hline $\mathrm{R}(02,03)^{\star * *}$ & -0.058 & -0.575 & 0,565 & $\mathrm{R}(02,03)$ & 0.1367 & 2.669 & 0,0076 & $\mathrm{R}(02,03)^{\star \star \star}$ & -0.0443 & -0.906 & 0,3648 & $\mathrm{R}(02,03)^{\star \star \star}$ & 0.0381 & 0.349 & 0,7271 \\
\hline $\mathrm{R}(01,04)^{\star * *}$ & 0.0613 & 0.616 & 0,5379 & $\mathrm{R}(01,04)^{\star \star *}$ & -0.026 & -0.492 & 0,6226 & $\mathrm{R}(01,04)^{\star \star \star}$ & 0.0416 & 0.878 & 0,3801 & $\mathrm{R}(01,04)^{\star \star \star}$ & 0.0565 & 0.391 & 0,6959 \\
\hline $\mathrm{R}(02,04)$ & 0.302 & 3.568 & 0,0004 & $\mathrm{R}(02,04)^{* * *}$ & -0.0377 & -0.509 & 0,611 & $\mathrm{R}(02,04)^{* * *}$ & -0.0825 & -1.346 & 0,1784 & $\mathrm{R}(02,04)^{* * *}$ & 0.02 & 0.123 & 0,9019 \\
\hline $\mathrm{R}(03,04)^{\star \star *}$ & -0.0895 & -0.879 & 0,3793 & $\mathrm{R}(03,04)^{\star \star \star}$ & -0.0366 & -0.678 & 0,4978 & $\mathrm{R}(03,04)$ & -0.1638 & -3.673 & 0,0002 & $\mathrm{R}(03,04)^{\star \star \star}$ & -0.0652 & -0.678 & 0,4975 \\
\hline \multicolumn{4}{|c|}{ Goodness-of-Fit Indexes } & \multicolumn{4}{|c|}{ Goodness-of-Fit Indexes } & \multicolumn{4}{|c|}{ Goodness-of-Fit Indexes } & \multicolumn{4}{|c|}{ Goodness-of-Fit Indexes } \\
\hline No Obsev & 443 & & & No Obsev & 1222 & & & No Obsev & 1423 & & & No Obsev & 432 & & \\
\hline $\mathrm{L}$ & -802.6817 & & & $\mathrm{~L}$ & -2037.465 & & & $\mathrm{~L}$ & -2419.887 & & & $\mathrm{~L}$ & -504.1722 & & \\
\hline Lo & -1205.176 & & & Lo & -2470.181 & & & Lo & -3005.137 & & & Lo & -622.6329 & & \\
\hline Pseudo R ${ }^{2}$ & 0,33397 & & & Pseudo $\mathrm{R}^{2}$ & 0,17518 & & & Pseudo $\mathrm{R}^{2}$ & 0,19475 & & & Pseudo $\mathrm{R}^{2}$ & 0,19026 & & \\
\hline AIC & 3.7954 & & & AIC & 3.39847 & & & AIC & 3.45311 & & & AIC & 2.46376 & & \\
\hline $\mathrm{BIC}$ & 4.14654 & & & $\mathrm{BIC}$ & 3.5615 & & & $\mathrm{BIC}$ & 3.58989 & & & $\mathrm{BIC}$ & 2.72745 & & \\
\hline HQIC & 3.93389 & 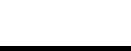 & & HQIC & 3.45983 & & & HQIC & 3.5042 & & & HQIC & 2.56787 & & \\
\hline
\end{tabular}

Highlighted the variables whose parameters have different sign between models

${ }^{*} X^{2}$ test significant at 0.05 level; all others significant at 0.01 level (except for the correlation matrix coefficients, which are significant over 0.05 level if they are marked with ${ }^{\star \star \star}$ ) $\left({ }^{*}\right) 01$ = ATHOME, 02 = PREPLAN, 03 = ASPLANNED 
If transit is planned to be used to go to a relaxing/napping/reading activities, there is a higher tendency to execute them as planned compared with driving a car. But if transit is planned to be used to go to an exercise or active sports activity, it is more likely that the activity is modified or deleted prior to execution. We have again that different activities (relaxing/napping/reading and exercise or active sports activity) in a similar context (planning to use transit) are scheduled in a different way. Although we have to consider here more information to explain the way they are scheduled: planning to use transit introduces a certain degree of flexibility, while planning long activities increases rigidity. This confirms results from Doherty (2006) and Doherty and Mohammadian (2007).

Respondents with a greater number of activities per day have a higher tendency to modify or delete relaxing/napping/reading activities prior to their execution. However, if we consider watching regular TV programs in the same context, respondents are more likely to execute them as planned. In general, the more activities planned, the more likely it is that they are modified or deleted prior to their execution (Ruiz et al, 2005). But if one considers planning of watching regular TV programs, as this is usually spontaneously done, there is less chance to be modified or deleted.

\section{CONCLUSIONS AND DISCUSSION}

The results presented in this paper support the hypothesis that scheduling decisions per activity type follow different mechanisms. There does not seem to be a single set of variables that consistently explains scheduling behaviour across activity types either at the aggregate level or at the disaggregate level. Using a rich dataset the following activity planning decisions were studied: location, time horizon and the execution of activities as planned. This analysis was carried out separately by activity types. In general, basic needs activities are mainly influenced by household characteristics. On the other hand, recreation/entertainment and drop off/pick up activities are more related to individual and activity characteristics. A combination of factors influences social activities. Many different types of activities with similar household, individual or activity characteristics are planned in different ways.

To confirm the previous findings, additional analysis was conducted using only recreation/entertainment activity sub-types, and adds the "with whom" planning decision, which distinguishes whether activities are done alone or with others. Overall, relaxing/napping/reading activities and doing exercise or active sports depend largely on household characteristics. But watching regular TV programs is explained mainly by individual characteristics. Email/internet related activities are influenced by a combination of household, individual and activity characteristics. In this later case we also have found that many different sub-types of activities with similar household, individual or activity characteristics are planned in different ways.

These findings provide indications of how to improve the current generation of activity-travel scheduling models.

- It is clear that a wide variety of detailed household, individual and activity attributes should be brought to bear when generating activity attributes, such as location, and whether activities are done alone. Activity scheduling models that rely on limited contextual information will miss many of these relationships. 
- Many activity types and sub-types can be conducted either at-home or out-of-home and it is possible to relate these substitutions to explanatory variables. Activity scheduling models that do not specify the nature of at-home activities miss out on these substitution effects.

- Activities conducted alone and joint activities of the same activity type are not planned independently, as is assumed in some activity scheduling models. Reflecting interdependencies in the generation of such related activities would be beneficial.

- Activity scheduling models that insert activities deterministically in order of aggregate activity type could be improved by reflecting the scheduling process more stochastically. This analysis has shown that every activity type has a stochastic propensity to be preplanned, and thus has some probability to be included in the skeleton schedule and some probability to be inserted spontaneously into a highly-specified schedule just prior to execution. Ignoring this stochasticity may lead to inaccuracies in the activity patterns that emerge from the scheduling process.

- The incidence of scheduling modifications can be at least partially explained by explanatory variables. Direct simulation of the incidence of activity modifications/deletions in the process of scheduling would not be consistent with the philosophy of most activity scheduling models (TASHA for example uses a process of activity insertion that assumes deterministic rules for activity modification/deletion for specific types of scheduling conflict). However, some validation could be done using the models developed here to assess the quality of these rules, and whether some degree of stochasticity might be warranted.

- There is clear heterogeneity in the decision processes for different activity types and subtypes. Thus it seems prudent to represent a greater disaggregation of activity types than is present in the current generation of activity scheduling models, in order to capture this heterogeneity.

- There are significant correlations between the outcomes of planning decisions regarding activity location, planning time horizon, the incidence of activity modifications, and with whom. Activity scheduling models that treat these decisions as independent could more accurately reflect the correlations found in this analysis.

Further research would include:

- Further analysis exploring differences among groups of activities defined not only by type but also by other characteristics, as suggested elsewhere in the literature.

- Using random parameter probit (RPP) specification to test for preference heterogeneity in dichotomous choice responses.

- Development and testing of a system of activity planning that is suitable to be incorporated within an operational activity scheduling microsimulation model such as TASHA. Such development could involve the direct incorporation of probit models similar to those developed in this paper, or could involve simpler refinements to the existing rule base to incorporate some of the insights attained in this exercise. 


\section{REFERENCES}

Akar, G., Clifton, K.J. and Doherty, S.T. (2009) How Travel Attributes Affect Planning Time Horizon of Activities, Transportation Research Record: Journal of the Transportation Research Board, 2132, 33-41.

Arentze, T.A. and Timmermans, H.J.P. (2000) Albatross: A Learning-Based Transportation Oriented Simulation System, European Institute of Retailing and Services Studies, Eindhoven.

Arentze, T.A., Timmermans, H.J.P., Janssens, D. and Wets, G. (2006) Modeling short-term dynamics in activity-travel patterns: From aurora to feathers. Presented at Innovations in Travel Demand Modeling Conference, Austin, Texas.

Arentze T.A., Timmermans H.J.P. (2009) A need-based model of multi-day, multi-person activity generation. Transportation Research Part B, 43(2), 251-265.

Auld, J., Mohammadian, A. and Doherty, S.T. (2008) Analysis of activity conflict resolution strategies. Transportation Research Record: Journal of the Transportation Research Board, 2054, 10-19.

Bellemans, T., Kochan, B., Janssens, D., Wets, G. and Timmermans, H. J. P. (2008) In the Field Evaluation of the Impact of a GPS-Enabled Personal Digital Assistant on Activity-Travel Diary Data Quality. Transportation Research Record: Journal of the Transportation Research Board, 2049, 136-143.

Clark, A.F. and Doherty, S.T. (2008). Examining the Nature and Extent of the Activity-travel Preplanning Decision Process. Transportation Research Record: Journal of the Transportation Research Board, 2054, 83-92.

Clark, A.F. and Doherty, S.T. (2010) A multi-instrumented approach to observing the activity rescheduling decision process. Transportation. 37(1), 165-181.

Clark, A.F. and Doherty, S.T. (2009). Activity Rescheduling Strategies and Decision Processes in Day-to-Day Life. Transportation Research Record: Journal of the Transportation Research Board, 2134, 143-152.

Doherty, S.T. (2000) An Activity Scheduling Process Approach to Understanding Travel Behavior. Paper presented at the 79th Annual Meeting of the Transportation Research Board (CD-ROM), Washington, D.C.

Doherty, S.T. and Miller, E.J. (2000) A computerized household activity scheduling survey. Transportation, 27, 75-97.

Doherty, S.T., Nemeth, E., Roorda, M.J. and Miller, E.J. (2004) Computerized household activity-scheduling survey for Toronto, Canada, Area. Transportation Research Record: Journal of the Transportation Research Board, 1894, 140-149.

Doherty, S. T. (2005) How far in advance are activities planned? Measurement challenges and analysis. Transportation Research Record: Journal of the Transportation Research Board, 1926, 41-49. 
Doherty, S. T. (2006) Should we abandon activity type analysis? Redefining activities by their salient attributes. Transportation, 33, 517-536.

Doherty, S.T., and Mohammadian, A. (2007) Validity of Using Activity Type to Structure TourBased Scheduling Models. Paper presented at the 86th Annual Meeting of the Transportation Research Board, (CD-ROM), Washington, D.C.

Ettema, D.F., Borgers, A.W.J. and Timmermans, H.J.P. (1994) Using interactive computer experiments for identifying activity scheduling heuristics. Paper presented at the $7^{\text {th }}$ International Conference on Travel Behaviour, Santiago, Chile.

Ettema, D., Borgers, A.W.J. and Timmermans, H.J.P. (2000), A simulation model of activity scheduling heuristics: an empirical test, Geographical and Environmental Modelling, 4, 175187.

Gärling, T., Kwan, M.P. and Golledge, G. (1994) Computational-process modeling of household activity scheduling. Transportation Research Part B, 25, 5, 355-364.

Greene, W.H. (2003). Econometric Analysis. Prentice Hall

Habib K.M.N., and Miller E.J. (2009) Modelling activity generation: a utility-based model for activity-agenda formation. Transportmetrica, 5 (1), 3-23

Hagerstrand, T. (1970). What about people in regional science? Papers of the Regional Science Association, 24, 7-21.

Hato, E. (2010) Development of behavioral context addressable loggers in the shell for travelactivity analysis, Transportation Research Part C, 18, 55-67.

Hayes-Roth, B. and Hayes-Roth, F. (1979) A cognitive model of planning. Cognitive Science 3, 275-310.

Joh, C.-H., Arentze, T.A. and Timmermans, H.J.P. (2003) Understanding activity scheduling and rescheduling behaviour: theory and numerical simulation. In B. Boots, et al. (eds.), Modelling Geographical Systems. Kluwer Academic Publishers, Dordrecht, 73-95.

Joh, C.-H., Arentze, T.A. and Timmermans, H.J.P. (2004) Activity-travel rescheduling decisions: empirical estimation of the Aurora model, Transportation Research Record: Journal of the Transportation Research Board, 1898, 10-18.

Joh, C-H, Doherty, S.T. and Polak, J.W. (2005) An analysis of the factors affecting the frequency and type of activity schedule modification. Transportation Research Record: Journal of the Transportation Research Board, 1926, 19-25.

Joh, C-H, Polak, J.W. and Ruiz, T. (2005) Characterizing global activity schedule adjustment behaviour using a sequence alignment method. Transportation Research Record: Journal of the Transportation Research Board, 1926, 26-32. 
Kang, H., Scott, D.M. and Doherty, S.T. (2009) Investigation of Planning Priority of Joint Activities in Household Activity-Scheduling Process, Transportation Research Record: Journal of the Transportation Research Board, 2134, 82-88.

Kitamura, R., S. Fujii and Y. Otsuka (1996) An analysis of induced travel demand using a production model system of daily activity and travel which incorporates time-space constraints. Presented at the Fifth World Congress of the Regional Science Association International, Tokyo.

Kwan, MP (1997) GISICAS: An activity-based travel decision support system using a GISinterfaced computational-process model. In: Ettema DF, Timmermans HJP (eds) ActivityBased Approaches to Travel Analysis, Pergamon, New York, 263-282.

Lee, M.S., Doherty, S.T., Sabetiashraf, R. and McNally, M.G. (2000) iCHASE: an Internet computerized household activity scheduling elicitor survey. Paper presented at the $79^{\text {th }}$ Annual Meeting of the Transportation Research Board, Washington, DC.

Lee, M.S. and McNally, M.G. (2006) An empirical investigation on the dynamic processes of activity scheduling and trip chaining. Transportation, 33, 6, 553-565.

Lee, M. and McNally, M.G. (2001) Experiments with a computerized self-administrative activity survey. Transportation Research Record: Journal of the Transportation Research Board, 1748, 125-131.

Miller, E.J. and Roorda, M.J. (2003) A prototype model of household activity/travel scheduling. In Transportation Research Record: Journal of the Transportation Research Board, 1831, 113121.

Mohammadian, A and Doherty, S.T. (2005) Mixed logit model of activity-scheduling time horizon incorporating spatial-temporal flexibility variables. Transportation Research Record: Journal of the Transportation Research Board, 1926, 33-40.

Mohammadian, A. and Doherty, S. T. (2006) Modeling Activity Scheduling Time Horizon: Duration of Time between Planning and Execution of Pre-Planned Activities. Transportation Research Part A, 40, 475-490.

Pendyala, R.M., Kitamura, R. and Reddy, D.V.G.P. (1995) A rule-based activity-travel scheduling algorithm integrating neural networks of behavioural adaptation. Paper presented at the EIRASS Conference on Activity-Based Approaches, Eindhoven.

Pendyala, R.M., Kitamura, R., Chen, C. and Pas, E.I. (1997) An activity-based microsimulation analysis of transportation control measures. Transport Policy, 4, 183-192.

Pendyala, R.M., Kitamura, R. Kikuchi, A., Yamamoto, T. and Fujji, S. (2005) FAMOS: Florida activity Mobility simulator. Paper presentet at the 84th Annual Meeting of the Transportation Research Board, CD-Rom, Washington D.C.

Rindsfüser, G., Mühlhans, H., Doherty, S.T. and Beckmann, K.J. (2003) Tracing the planning and execution of activities and their attributes: design and application of a hand-held scheduling process survey. Paper presented at the $10^{\text {th }}$ International Conference on Travel Behaviour Research (IATBR), Lucerne. 
Roorda, M.J., and Miller, E.J. (2004) Toronto Activity Panel Survey: demonstrating the benefits of a multiple instrument panel survey. Paper presented at the $7^{\text {th }}$ International Conference on Travel Survey Methods, Costa Rica.

Roorda, M. J., Lee-Gosselin, M., Doherty, S.T., Miller, E.J. and Rondier, P. (2005) Travel/activity panel surveys in the Toronto and Quebec City regions: Comparison of methods and preliminary results. Paper presented at PROCESSUS Second International Colloquium on the Behavioural Foundations of Integrated Land-use and Transportation Models: Frameworks, Models and Applications. CD-ROM. Toronto.

Roorda, M.J. and Miller, E.J. (2005) Strategies for resolving activity scheduling conflicts: An Empirical Analysis. In H.J.P. Timmermans Progress in Activity-Based Analysis, Elsevier, Oxford, 203-222.

Ruiz, T. (2005) Design and implementation of an activity scheduling survey using Internet. In H. Timmermans Progress in Activity-Based Analysis, Elsevier, Oxford, 373-388.

Ruiz, T., Polak, J.W. and Joh, C.H. (2005) An empirical analysis of the factors affecting the resolution of activity scheduling conflicts. Transportation Research Record: Journal of the Transportation Research Board, 1926, 50-60.

Ruiz, T., and Timmermans, H.J.P. (2006) Changing the timing of activities in resolving scheduling conflicts. Transportation, 33, 5, 429-445.

Ruiz, T. and Roorda, M.J. (2008) Analysis of Planning Decisions During the ActivityScheduling Process. Transportation Research Record: Journal of the Transportation Research Board, 2054, 46-55.

Timmermans, H. J. P. (2001) Models of Activity Scheduling Behaviour. Mobilitat und Stadt, Stadt Region Land, 71, 33-47.

Timmermans, H.J.P., T.A. Arentze and C.-H. Joh (2001) Modelling the effects of anticipated time pressure on the execution of activity programs, Transportation Research Record Journal of the Transportation Research Board, 1752, 8-15.

Timmermans H.J.P., Zhang J.Y. (2009) Modeling household activity travel behavior: Examples of state of the art modeling approaches and research agenda. Transportation Research Part B, 43(2), 187-190.

van Bladel, K., T. Bellemans, D. Janssens, and G. Wets (2009) Activity Travel Planning and Rescheduling Behavior: Empirical Analysis of Influencing Factors, Transportation Research Record: Journal of the Transportation Research Board, 2134, 135-142. 